\title{
ROTACIÓN Y AUSENTISMO LABORAL EN EL PARQUE INDUSTRIAL DE VILLA EL SALVADOR
}

Pedro L. Tito Huamani*

pedrotito18@hotmail.com

\begin{abstract}
RESUMEN
El ausentismo y la rotación laboral son indicadores de gestión que permiten medir el nivel de satisfacción que tiene el trabajador en su centro laboral. Se entiende por ausentismo laboral como el retiro permanente del personal de la organización donde labora. También es considerado como el abandono o ausencia de los trabajadores y de los deberes que debe cumplir. Además no solo se considera como la ausencia en el puesto de trabajo sino también como la no realización por parte del trabajador de la contraprestación de sus servicios a cambio de un salario, es decir, no realiza labores productivas para la empresa donde se desempeña. La Organización Internacional del Trabajo $($ OIT 2,008$)$ la define como "[...] la no asistencia al trabajo por parte de un empleado que se pensaba iba a asistir, quedando excluidos los períodos vacacionales y las huelgas; y el ausentismo laboral de causa médica, como el período de baja laboral atribuible a una incapacidad del individuo, excepción hecha para la derivada del embarazo normal o prisión".

Por otro lado se entiende por rotación laboral como aquella fluctuación del personal entre una organización y su ambiente, esto quiere decir que el intercambio de personal entre la organización y el ambiente se define por el volumen de personas que ingresan y salen de la organización. Como herramienta de gestión, esta variable mide la estabilidad en el empleo, que se entiende por el número de accesos y separaciones (ingresos y salidas del personal) en un periodo de tiempo.

Ambos fenómenos fueron investigados en el emporio empresarial Mype ${ }^{1}$ del Parque Industrial de Villa El Salvador (PIVES), demostrando así nuestras premisas que postulaban que tanto el ausentismo como la rotación afectan la productividad laboral, y exceden significativamente la tasa promedio del sector productivo en nuestro medio.
\end{abstract}

Palabras claves: Rotación laboral, ausentismo laboral, productividad laboral, PIVES.

\footnotetext{
* Doctor en Ciencias Administrativas UNMSM. Magíster en Gestión Empresarial y Licenciado en Administración UNMSM. Director del Instituto de Investigación de la Facultad de Ciencias Administrativas- UNMSM. Diplomas de Reconocimiento por el Vice-Rectorado de Investigaciones-UNMSM, por actividades y publicación de Investigaciones Científicas (2012 y 2007). Docente Investigador de la UNMSM. Docente de Post Grado UNMSM y Profesor visitante de las Escuelas de Post Grado, en la UNP- Piura, UNT- Trujillo. UNLG- Ica, UNA- Puno, UNSCH- Ayacucho. Consultor en Gestión Humana y Comportamiento Organizacional.

1 Para los propósitos de la presente investigación, Mype se denomina a la Micro y Pequeña empresa.
} 


\begin{abstract}
Absenteeism and labor turnover are indicators of management that allows us to measure the level of satisfaction of the worker in his workplace. Absenteeism is defined as the permanent withdrawal of the staff of the organization where you work. It is also seen as an abandonment or absence of workers and the duties to be fulfilled. Also not only considered as the absence in the workplace but also as non-performing by the employee of the consideration of their services in exchange for wages, ie not perform productive work for the company where he works. The OIT defines as "nonattendance at work by an employee who was thought he would attend, excluding holiday periods and strikes, and absenteeism of medical cause, as the period of sick leave attributable to an inability the individual, except for the derivative of normal pregnancy or imprisonment".

On the other hand means that labor turnover as staff fluctuation between an organization and its environment, this means, exchange of personnel between the organization and the environment is defined by the volume of people entering and leaving the organization. As a management tool, this variable measures the stability of employment, which is defined as the number of hits and separations (inflows and outflows of staff) over a period of time.

Both phenomena were investigated in the business empire Mype Industrial Park of Villa El Salvador (PIVES), proving our assumptions postulating that both absenteeism and turnover affect labor productivity, and significantly exceed the average rate of the productive sector in our midst.
\end{abstract}

Keywords: Labor turnover, absenteeism, labor productivity, PIVES.

\section{INTRODUCCIÓN}

El presente trabajo se centra en el estudio de la rotación y el ausentismo laboral en las pequeñas y medianas empresas, en especial en aquellas agrupadas en emporios empresariales. Debido a que el ausentismo y la rotación laboral son indicadores de gestión de una organización, resulta de gran importancia el análisis de éstas y la relación con otras variables en la gestión humana.

En la actualidad el mercado de demanda laboral peruano está conformado según estudios por las Mypes que, junto con las medianas empresas, representan el 98\% del sector empresarial nacional. Muchas de estas Mypes se encuentran ubicadas en conglomerados empresariales, tales como el Parque Industrial de Villa El Salvador (PIVES) o en emporios comerciales, como es el caso de Gamarra. Estos dos casos son emblemáticos en el Perú, de allí nuestro interés en investigar. En el caso del PIVES, concentra a una innumerable cantidad de pequeñas empresas fabricantes de muebles de madera, metalmecánica, calzado y confecciones de ropa.

El ausentismo y la rotación laboral son indicadores de relevancia en el siglo XXI, dado que estos se asocian a la gestión del talento humano que posee la empresa. El personal, al encontrarse desmotivado, lo que hace es faltar o cambiarse de trabajo, afectando directamente a la productividad. El entorno actual exige de colaboradores que sean cada vez más calificados. Dado que muchas variables están asociadas al ausentismo y rotación laboral, existe una relación significativa con la satisfacción de los trabajadores, de allí que estadísticamente demostraremos que existen otras variables que se relacionan con los dos elementos materia de la presente investigación.

\section{CONTEXTO ORGANIZACIONAL DEL PARQUE INDUSTRIAL DE VILLA EL SALVADOR}

En la década del 70, el Estado Peruano en previsión del crecimiento poblacional, dispone de un terreno y diseña el futuro Parque Industrial para instalar a grandes y medianas empresas. En 1987 su concepción cambió, convirtiéndose en una experiencia inédita de concentración y consolidación de micro y pequeñas empresas, articulada según el Plan Integral de Desarrollo del Distrito de Villa El Salvador.

Michel Azcueta, el primer alcalde del distrito, junto con la Comunidad Urbana Autogestionaria de Villa El Salvador (CUAVES) y la Central de Pequeños y Medianos Empresarios de Villa el Salvador (APEMIVES), proponen a la Organización de las Naciones Unidas para el Desarrollo Industrial (ONUDI) realizar un estudio que brinde sustento técnico a la propuesta de reubicar en dicha zona industrial a los talleres productivos que venían funcionando en la zona urbana. Desde un inicio, el gobierno local fue el principal impulsor de este 
proyecto, en su rol de promotor y facilitador del desarrollo local. Así, el distrito de Villa El Salvador pasó de ser ciudad dormitorio a una de carácter eminentemente productivo.

Esta experiencia de desarrollo económico del distrito de Villa El Salvador es el resultado del entusiasmo y esfuerzo de sus pobladores, quienes venciendo las dificultades políticas, económicas y sociales que a lo largo de las últimas tres décadas ha conocido el Perú, osaron impulsar un parque industrial para la micro, pequeña y mediana empresa. A la fecha, el parque industrial es un polo de inversión y empleo, por el movimiento económico que genera en el cono sur de Lima, subraya la importancia urbana, económica y política en el país.

\section{Estructura del Parque Industrial según gremios empresariales}

Este es un aspecto importante en la conformación y vida del PIVES. Los empresarios tuvieron que asociarse para cumplir con el requisito fundamental de estar agremiado para postular a un lote ubicado en la zona industrial donde instalar su taller.

El siguiente cuadro grafica la organización del Parque Industrial en ese entonces.

Cuadro $\mathrm{N}^{\circ}$ 1. Organización del Parque Industrial ${ }^{2}$

\begin{tabular}{|l|c|c|c|}
\hline \multicolumn{1}{|c|}{ SECTORES } & LOTES & ASOCIADOS & \% DE \\
\hline & ASIGNADOS & POR GREMIO & ASOCIATIVIDAD \\
\hline Carpintería & 278 & 80 & $29 \%$ \\
\hline Metalmecánica & 203 & 95 & $47 \%$ \\
\hline Calzadosy Cuero & 75 & 40 & $53 \%$ \\
\hline Confecciones & 124 & 40 & $32 \%$ \\
\hline Fundición & 97 & 36 & $37 \%$ \\
\hline Artesanía & 70 & 34 & $49 \%$ \\
\hline Alimentos & 54 & 12 & $22 \%$ \\
\hline Pymes Varios & 144 & 120 & $85 \%$ \\
\hline Total & 1045 & 457 & $44 \%$ \\
\hline
\end{tabular}

Fuente: APEMIVES, 2010.

\section{Composición del Parque Industrial por sectores}

Las actividades principales son carpintería $(29,8 \%)$ y metalmecánica $(29,5 \%)$. Ambas mueven aproximadamente el $59 \%$ de la producción de todo el Parque Industrial, superando ampliamente a los otros rubros. Confecciones tiene el $12,4 \%$; calzado el 11,1\% y artesanía el 9,5\%. Los tres sectores constituyen un segundo bloque fuerte de productores del parque industrial. Las actividades con menor presencia son fundición $(4,1 \%)$ y entre alimentos, marmolería, plásticos, productos del papel, y productos químicos bordean el 3,4\%.

\section{El empleo}

Según el último censo económico empresarial del Ministerio de Producción (PRODUCE), el sector de carpintería es el que ha logrado tener el mayor impacto con relación a los empleos generados en el Parque Industrial, con el 38\% de participación. Esto demuestra la relevancia de esta actividad para el conjunto del PIVES. Le sucede metalmecánica con $27 \%$, confecciones con $11 \%$ y calzado con $10 \%$.

\section{Figura $N^{\circ} 1$. Empleos generados en el parque industrial según sectores}

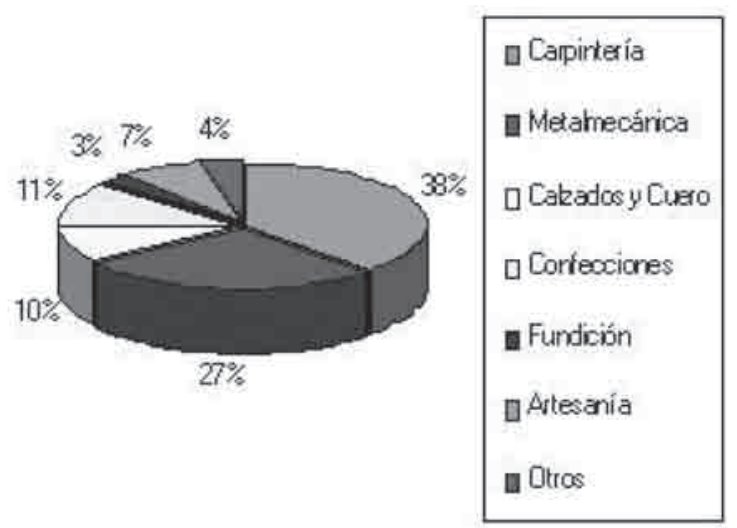

Fuente: APEMIVES, 2010.

\section{PLANTEAMIENTO DEL ESTUDIO (FUNDAMENTA- CIÓN DEL PROBLEMA, OBJETIVOS, IMPORTANCIA DE LA INVESTIGACIÓN)}

La rotación y el ausentismo laboral se han convertido en factores determinantes en el desempeño de una organización, dado que incluye el buen manejo de los colaboradores; es decir, involucran una buena gestión del conocimiento, la inteligencia emocional, entre otras. Además, los altos índices de ausentismo y rotación laboral se han convertido en factores demandantes de costos para la empresa. En el Perú se registran altos índices de rotación laboral que llegan a un $20,7 \%$, mientras que en Latinoamérica el estándar de rotación es de un 10,9\%; así se nota que existe una brecha de rotación laboral de nuestro país en comparación del resto de Latinoamérica.

La presidenta ejecutiva de DBM Perú, Inés Temple, afirma: "[...] el nivel de rotación no solo se debe al avance de la economía nacional, sino también a que los sueldos en el mercado laboral se encuentran atrasados desde hace mucho tiempo $\mathrm{y}$ ante el surgimiento de una mejor oferta salarial

\footnotetext{
2 Distribución según gremios al año 2007, vale decir, a 10 años de funcionamiento.
} 
no dudan en aceptar" (El Comercio, 2011). Según Adolfo Gonzales, director de Tasa Worlwil de Perú, este alto índice de rotación en el país se debe a que en el Perú existe una reestructuración empresarial y, además, se desarrollan cada vez más productos con valor agregado. "Hay un cúmulo de oportunidades de desarrollo en el país en la medida en que las empresas asumen nuevos retos y estilos de dirección. Entonces, es allí cuando los ejecutivos peruanos se van reubicando", afirma Gonzales (El Comercio, 2011).

De acuerdo con la teoría consultada sobre ausentismo y rotación laboral y el razonamiento lógico, es de notar que existe una estrecha relación entre la satisfacción, el ausentismo y rotación laboral. Esto quiere decir, a menor satisfacción nuestros colaboradores tienden a faltar y/o cambiarse de empresa (que generalmente suele ser desfavorable para la empresa de origen porque implica mayores costos). Así, el nivel de satisfacción o insatisfacción debe comprenderse desde motivos salariales, trato que reciben de su jefe, cultura y clima laboral, entre otros.

El propósito de esta investigación es identificar las causas y consecuencias del ausentismo y rotación laboral en el emporio empresarial Mype más representativo de Lima Metropolitana, como lo es el parque industrial de Villa El Salvador, y ver cómo éstas influyen en el desempeño de sus colaboradores, además de mostrar alternativas o estrategias para reducir tales índices.

\section{Formulación y sistematización del problema}

La situación descrita me permite plantear la siguiente interrogante general:

¿Cuáles son los niveles de índices de ausentismo y rotación laboral, y como impactan en la productividad en las empresas ubicadas en el Parque Industrial de Villa el Salvador?

La respuesta a esta pregunta está condicionada según como se responda a las interrogantes específicas:

- ¿Cómo influye la edad en el ausentismo y rotación laboral en el Parque Industrial de Villa El Salvador?

- ¿Cuánto influyen las capacitaciones en el rendimiento y comportamiento de las personas para reducir los índices de ausentismo y rotación laboral?
- ¿Qué relación existe entre insatisfacción laboral y rotación de personal?

\section{Objetivos de la investigación}

- General. Explicar las causas y consecuencias del ausentismo y rotación laboral en el emporio empresarial Mype del Parque Industrial de Villa El Salvador y analizar cómo éstas se reflejan en la productividad de los colaboradores.

- Específicos:

- Analizar el impacto de las variables como la edad, grado de instrucción, género y actividades recreativas en el ausentismo y rotación en el Parque Industrial del Villa El Salvador.

- Proporcionar estrategias que ayuden en la disminución de altos índices de ausentismo y rotación laboral, en el Parque Industrial de Villa El Salvador.

- Identificar las motivaciones que cobran mayor fuerza para el ausentismo y rotación laboral, respectivamente.

\section{MARCO TEÓRICO Y DEFINICIÓN DE CONCEPTOS}

\section{Ausentismo laboral}

El ausentismo o absentismo laboral es definido como la ausencia del personal en la organización donde se desempeña. También es considerado como el abandono o ausencia del trabajador y de los deberes que debe cumplir dentro de horario establecido. Pero al ausentismo no solo se considera como la ausencia en el puesto de trabajo sino también como la no realización por parte del trabajador de la contraprestación de sus servicios a cambio de un salario. Es decir, no realiza labores productivas para la empresa donde se desempeña.

La OIT define al absentismo laboral como "[...] la no asistencia al trabajo por parte de un empleado que se pensaba iba a asistir, quedando excluidos los períodos vacacionales y las huelgas. El ausentismo laboral de causa médica, como el período de baja laboral atribuible a una incapacidad del individuo, excepción hecha para la derivada del embarazo normal o prisión" (OIT y Universidad Nacional Autónoma de México, 2008). Mientras que la Real Academia Española tiene un concepto similar a este refiriéndose al absentismo como la "Costumbre de abandonar el desempeño de funciones y deberes ajenos a un puesto" (Diccionario de la Real Academia Española, 2011). 
Muchos casos de ausentismo laboral en nuestro medio se debe a que los trabajadores están insatisfechos o no comprometidos con la organización, es decir, no existe relación entre los empleados que garantice el logro de los objetivos de la organización, causando improductividad de la empresa. Según este concepto existe una relación negativa o inversa entre la satisfacción de los trabajadores y el ausentismo laboral, por cuanto, al disminuir la satisfacción de los trabajadores, generará una tendencia a la falta (ausentismo). "Existe una relación negativa constante entre la satisfacción y ausentismo laboral. El empleado insatisfecho tiende a faltar más al trabajo, aunque debemos considerar, las empresas que no tienen una política de prestaciones por enfermedad, están favoreciendo el ausentismo, incluso en aquellos que puedan estar contentos en sus trabajos" (Morán, 2005, p. 125).

El ausentismo laboral es un fenómeno que se ha ido intensificando en los últimos años, convirtiéndose en uno de los problemas tanto de empresas nacionales como internacionales. Este es un indicador de gestión puesto que tiene grandes repercusiones en la empresa. A nivel macro tiene un impacto significativo en el Producto Bruto Interno en cualquier país. Diversos estudios relacionan al ausentismo con diferentes razones y/o causas, como el caso del estrés que refleja la presión del ambiente laboral, el trato del jefe, los bajos salariales, entre otros.

Michael G. Aamodt (2010, p. 388) menciona en su libro "Psicología Industrial/organizacional" que "[...] las organizaciones hacen grandes esfuerzos para reducir el número de inasistencias no programadas. Para que estos esfuerzos sean eficaces, es importante que entendamos por qué los colaboradores faltan al trabajo. Esto es, los castigos reducirán el ausentismo solo si los empleados toman decisiones conscientes acerca de la asistencia. De la misma forma, los programas de salud incrementarán la asistencia solo si el ausentismo se debe en mayor medida a enfermedades".

Según Muchinsky (2007, p. 79) "El ausentismo tiene causas sociales, individuales y organizacionales, y afecta a individuos, compañías e incluso a sociedades industriales". Al provenir el ausentismo de factores relacionados al trabajador y el ambiente laboral, estos repercutirán en la productividad de la empresa y en la sociedad. De allí que no solo afecta al individuo.
- Tipos de Ausentismo. Según Chiavenato (2007, p. 243), los tipos de ausentismo laboral que se presentan en las organizaciones son:

- Ausentismo parcial. En este tipo de ausentismo solo se considera el personal en actividad normal y únicamente las faltas y retardos convertidas en horas, pero relacionadas con faltas injustificadas por certificados médicos, faltas por motivos médicos no justificados, retrasos por motivos justificados o no justificados.

- Ausentismo general (mixto). Este tipo de ausentismo se refiere todo lo relacionado con el personal ausente durante un periodo prolongado de tiempo, a su vez, incluye ausencias amparadas legalmente, tales como vacaciones, licencias de toda clase, ausencias por enfermedad, maternidad y accidentes de trabajo.

Por el otro, tenemos diferentes posturas respecto a la tipología del ausentismo. Para Reyes Ponce (2000, p. 252), el ausentismo se clasifica de la siguiente manera: ausentismo mental y ausentismo físico, este último se divide en justificado e injustificado y cada uno de ellos en parcial o total, según se prolongue la ausencia a lo largo de toda la jornada o solo parte de lo que dure la misma.

- Ausentismo mental. Puede conceptualizarse como la asistencia física del trabajador, pero su pensamiento se encuentra distante, por lo que se presume que dicho comportamiento influye en la fluctuación de los índices de productividad en forma negativa. Sin embargo, existe la salvedad de que no toda fluctuación de los índices mencionados podría ser atribuida a este fenómeno. Para Marta Romo y Nekane Rodríguez (2010, p.144), este tipo de ausentismo también se le conoce como ausentismo emocional y ausentismo presencial. "Ausentismo emocional: son los trabajadores que están físicamente pero no emocionalmente. Son pero no están. Parece que trabajan, pero no rinden. Por ejemplo tenemos las personas que sí realizan su tarea pero no dan lo mejor de ellos mismos. No liberan todo su potencial. En tanto el ausentismo presencial: son los profesionales que estando en su puesto de trabajo, hacen otro tipo de tareas diferentes para las que fueron contratados. Por ejemplo, simulan trabajar cuando están navegando por Internet". 
- Ausentismo físico. Es toda inasistencia personal a las labores cotidianas pactadas contractualmente con la empresa; ese tipo de ausentismo se divide en físico justificado y en físico no justificado. El físico justificado es la inasistencia a las labores cotidianas que derivan de una incapacidad o imposibilidad real de acudir al centro de trabajo. Esta inasistencia puede obedecer a factores educativos, como por ejemplo: estar disfrutando de una beca oficial, o factores médicos tales como sufrir incapacidad maternal o post operatoria, así como estar atravesando por una enfermedad grave o por haber sufrido un accidente de trabajo, u otros. Obedece también a factores de tipo laboral como encontrarse en el cumplimiento de una comisión oficial que obligue a ausentarse al trabajador y finalmente a condiciones jurídicamente reglamentada, como el disfrute de vacaciones y descansos semanales o días festivos.

Este tipo de ausentismo también es denominado ausentismo laboral por Marta Romo y Nekane Rodríguez (2010, p.144). Según tales autores "Ausentismo laboral: son las personas que en apariencia no pueden asistir al trabajo por una causa médica debido a alguna enfermedad que padezca. El problema empieza cuando estas enfermedades se alargan sin causa justificada aunque estén respaldadas por un informe clínico".

El ausentismo físico no justificado o injustificado se define como la inasistencia no esperada de un empleado a su centro laboral, explicando motivos ficticios o no justificados. Este a su vez se clasifica en total o parcial. El ausentismo físico injustificado es total, cuando la ausencia se prolonga a lo largo de toda la jornada, como el caso de faltas, licencias e incapacidades ficticias. El ausentismo físico injustificado es parcial, temporal o incompleto cuando la ausencia no abarca la totalidad de la jornada, es decir, cuando se a llegado tarde, retirado temprano, o ha solicitado permiso para resolver un asunto en particular.

En la Figura $\mathrm{N}^{\circ} 2$ se distingue de manera más objetiva los criterios utilizados en la clasificación del ausentismo físico y los distintos casos que suelen presentarse

Figura $\mathrm{N}^{\circ} 2$. Tipos de ausentismo



Fuente: Elaboración Propia.

\section{Rotación laboral}

Se entiende por rotación laboral como aquella fluctuación del personal entre una organización y su ambiente. Esto quiere decir, el intercambio de personal entre la organización y el ambiente, definido por el volumen de personas que ingresan y salen de la organización. Stephen Robbins (2009, p. 29) define a la rotación en términos sencillos: "La rotación es el retiro permanente de una organización, y puede ser voluntario o involuntario".
Sin embargo, esta definición no considera los ingresos de personal que se dan en la organización, es decir, no considera a la organización como un sistema abierto.

El retiro del personal se da -generalmentecuando los trabajadores tienen un bajo nivel de satisfacción o tienen un bajo compromiso con la organización. Es por ello que suelen cambiar de trabajo, esperando conseguir tales carencias en otras organizaciones. 
Por otro lado, es importante reconocer que es inevitable la rotación del personal, dado que la organización de por si es dinámica y mantiene ese dinamismo con su ambiente (la sociedad), en la perspectiva de crecer y se desarrollarse en el tiempo.

En términos de gestión, esta variable mide la estabilidad en el empleo y representa un indicador que se calcula en un periodo de tiempo, midiendo la totalidad de transiciones ${ }^{3}$ que son el número de accesos y separaciones (ingresos y salidas del personal) en un periodo de tiempo de "t-1" y " $\mathrm{t}$ ".

Desde el punto de vista económico la rotación laboral es el resultado del flujo de trabajadores que entran y salen de los empleos en un período de tiempo. Esto quiere decir, tras la variación porcentual se encuentran movimientos de la mano de obra que pueden ser significativos. En el extremo, una variación del empleo de $0 \%$ no implica necesariamente inmovilidad en el mercado, puede ser resultado de considerables y equiparadas entradas y salidas de trabajadores.

Figura $\mathrm{N}^{\circ} 3$. La rotación laboral

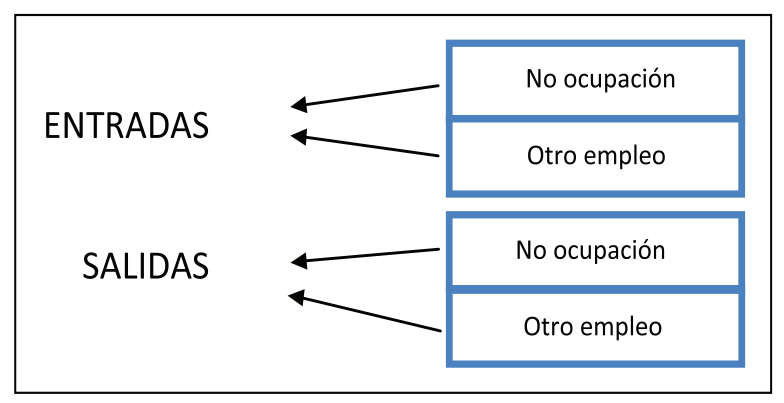

Fuente: MTPE - Programa de Estadísticas y Estudios Laborales (2010)

Desde la otra óptica, la rotación también se da porque los empleadores desean contratar a personas que tienen mayor desempeño en la organización y un espíritu proactivo ${ }^{4}$. El tema pasa porque los empleadores promueven la rotación controlada, porque contratar personas para que cambien de trabajo en demasía, perjudica a la organización. Desde esta perspectiva la rotación laboral implica un costo elevado, "[...] aunque las tasas de rotación del personal fluctúan de un año a otro. Cerca de $1,4 \%$ de los trabajadores de una organización se va cada mes ( $16,8 \%$ cada año). La rotación del personal es un problema porque el costo de perder a un empleado en Estados Unidos se estima en 1,5 veces el salario del mismo. Por tanto, si el sueldo anual de un empleado es de US\$ 40.000, el costo de reemplazarlo será de US\$ 60.000 dólares" (Aamodt, 2010, p. 393).

Existen dos clases de costos (visibles y ocultos), que determinan el costo total de la rotación del personal. Dentro de los costos visibles se encuentran la publicidad para la captación de nuevos prospectos, sueldo de los trabajadores que realizan la selección del personal, la inducción y socialización del nuevo trabajador en la organización, entre otros. Entre los costos ocultos se encuentran la disminución de la productividad ante la salida del trabajador, la pérdida de la capacitación que se le dio a ese trabajador y el costo de capacitar al nuevo trabajador. "El costo de reclutar, seleccionar y capacitar al personal nuevo, pueden ser en extremo significativos para la organización" (Muchinsky, 2007, p. 79). El costo real de rotación del personal para cualquier puesto, se puede calcular con mayor exactitud aplicando procedimientos estadísticos y matemáticos.

Uno de los factores que intervienen al momento de medir la rotación laboral es la voluntariedad, es decir, si el trabajador fue despedido, renunció o simplemente se encuentra insatisfecho con su ambiente laboral. También se encuentra el factor de la funcionalidad, vale decir, si el empleado se estaba desempeñando en su trabajo de forma efectiva o inefectiva. "Williams y Livingstone materializaron estudios que examinaron la relación entre el movimiento de personal y desempeño, concluyendo aquellos que se desempeñaban mal, tenían mayores probabilidades de renunciar en forma voluntaria, en relación a los que se desempeñaban bien” (Muchinsky, 2007, p. 79).

En otros contextos, la rotación laboral resulta beneficiosa siempre y cuando la salida de la organización sea de empleados improductivos o con un bajo nivel de desempeño. Muchas veces es usado como estrategia y representa una oportunidad para las empresas de obtener personal calificado y con mayores cualidades y aptitudes que los trabajadores salientes. Así, la organización logra que se incorporen trabajadores con ideas nuevas y frescas, con el agregado de que al implementarse el modelo de la gestión del conocimiento, logran que el nuevo trabajador pueda compartir sus conocimientos con trabajadores actuales.

\footnotetext{
3 Las transiciones se refieren a los accesos y separaciones, no al número de personas involucradas.

4 A esto se llama rotación involuntaria del personal
} 
- Tipos de rotación:

- Voluntario. El mismo trabajador presenta su carta de renuncia.

- Obligatorio. La gerencia despide al trabajador, con lo que obliga a buscar otro puesto de trabajo.

\section{Causas de rotación y ausentismo laboral}

Tanto la rotación como el ausentismo laboral están influenciados primordialmente por dos factores: la desmotivación y la insatisfacción laboral, por lo que podemos afirmar que los motivos o causas más importantes que implican la salida de trabajadores, así como las faltas, son fundamentalmente de índole laboral.

La rotación y ausentismo laboral también se manifiestan de diferentes maneras, según la edad, sexo, territorio geográfico, nivel ocupacional y la antiguiedad en la organización.

- La rotación y ausentismo laboral según la edad. Los trabajadores jóvenes tienden a cambiar o faltar con mayor frecuencia que las personas mayores. Esto se debe, primordialmente, a la poca experiencia laboral e inestabilidad de los trabajadores jóvenes.

- La rotación y ausentismo laboral según el sexo. En las mujeres, la fluctuación del índice de rotación laboral tiende a incrementarse más por motivos personales. En el caso de los varones el índice de rotación se incrementa por motivos laborales, al igual que el ausentismo laboral. A esto debemos adicionar a que las mujeres tienen mayores responsabilidades en el hogar y la familia.

- La rotación y ausentismo laboral según el territorio geográfico. La rotación laboral tiende a ser mayor cuando el territorio geográfico es grande. Lo contrario, tiende a disminuir cuando el territorio es pequeño, dado que existe una menor oferta laboral; por consiguiente, las personas tienen pocas posibilidades de conseguir trabajo. En el caso del ausentismo el problema de la distancia del hogar al trabajo también podría ser un factor perjudicial que contribuiría al incremento del índice de ausentismo laboral.

- La rotación laboral y ausentismo según nivel ocupacional. Los índices de rotación laboral se relacionan directamente con la calificación de mano de obra. Dicho de otro modo, cuanto mayor formación y responsabilidad tiene el trabajador, tenderá a faltar menos, a diferencia de aquel otro que por su formación cumple labores operativas e irrelevantes.

Por todo lo mencionado, se demuestra que las variables motivación y satisfacción laboral son causas fundamentales que influyen en la rotación y ausentismo laboral.

\section{Definición de conceptos}

- Mype. Micro o pequeña empresa que, por lo general, responde a la iniciativa del propietario. Se caracteriza por tener un pequeño capital y contar con un reducido número de colaboradores.

- Productividad. Relación entre lo producido y los medios empleados, tales como mano de obra, materiales, energía, etc. Desde el punto de vista laboral, un trabajador será productivo si comparativamente tienen mejores resultados, utilizando óptimamente los recursos que se le asigna.

- Rotación laboral. Es el movimiento de colaboradores a nivel externo de la empresa. Dicho de otro modo, salida de colaboradores actuales de la empresa e ingreso de nuevos trabajadores a la misma empresa.

- Ausentismo laboral. Viene a ser la ausencia física del trabajador en su puesto de trabajo. Cuando hablamos de ausencia nos referimos fundamentalmente de la ausencia del trabajador que falta pudiendo venir a trabajar.

\section{METODOLOGÍA}

\section{Tipo de investigación}

De acuerdo con los objetivos, la presente investigación es de carácter aplicativo, y según el nivel de profundidad, reúne las características de ser un estudio explicativo.

\section{Diseño de investigación}

Para el trabajo de campo de la presente investigación se diseñaron formatos de encuestas que se aplicaron a los trabajadores. Adicionalmente, se recurrió a entrevistas en profundidad dirigidas a directivos y/o propietarios de empresas ubicadas en el Parque Industrial de Villa El Salvador. 


\section{Población}

La población de esta investigación está conformada por el total de colaboradores del Parque Industrial de Villa El Salvador, provincia y departamento de Lima. De acuerdo a la información que dispone la Gerencia de Desarrollo Económico del distrito de Villa El Salvador, asciende a un total de 20.000 trabajadores, aproximadamente.

\section{Muestra}

La muestra utilizada en la presente investigación está conformada por 150 trabajadores del emporio empresarial Mype del Parque Industrial de Villa El Salvador.

\section{ANÁLISIS E INTERPRETACIÓN DE LOS RESULTADOS LOGRADOS}

A continuación se presentan los resultados del trabajo de campo. En esta parte es importante precisar que el instrumento adecuado para recopilar información primaria fue la encuesta. Dicho instrumento se aplicó en forma aleatoria.

Veamos los resultados estadísticos del trabajo de campo, fundamentalmente desde un análisis bivariable, vale decir, mediante el análisis del cruce de dos variables.

Figura $\mathrm{N}^{\circ} 4$. Rotación versus motivo de rotación

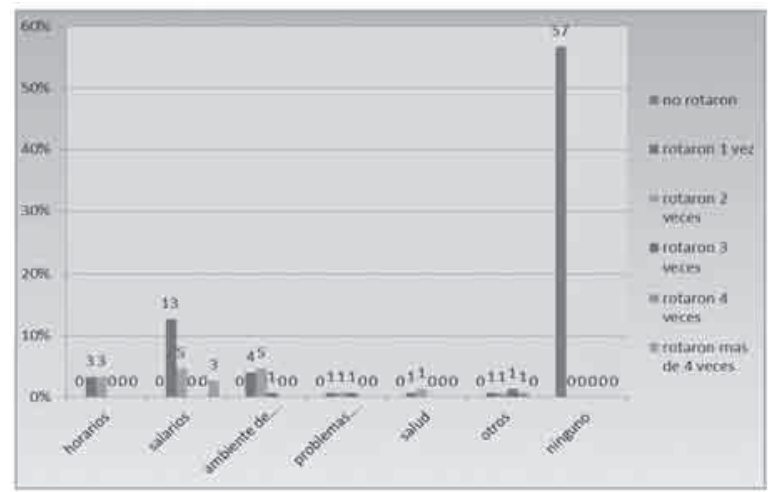

Fuente: Elaboración Propia

El 57\% de personas de un total de 150 que trabajan en el emporio comercial del Parque Industrial del distrito de Villa El Salvador no cambió de trabajo en los últimos años. El 13\% de personas del total de 150 que laboran en el mencionado emporio cambió de trabajo una vez, por el factor salario; el 5\% cambió dos veces por el ambiente laboral; mientras que sólo un 3\% cambió más de cuatro veces por motivos salariales. Se puede observar que la gran mayoría de personas no cambió de trabajo, esto como veremos más adelante, la mayoría de los trabajadores no tienen oficio u estudio técnico que les permita encontrar con facilidad otro empleo. Por otro lado, las personas que sí cambiaron de empleo son aquellas que, gracias a sus conocimientos técnicos, pueden encontrar empleo con facilidad.

Figura $\mathrm{N}^{\circ}$ 5. Ausentismo y motivo de ausentismo

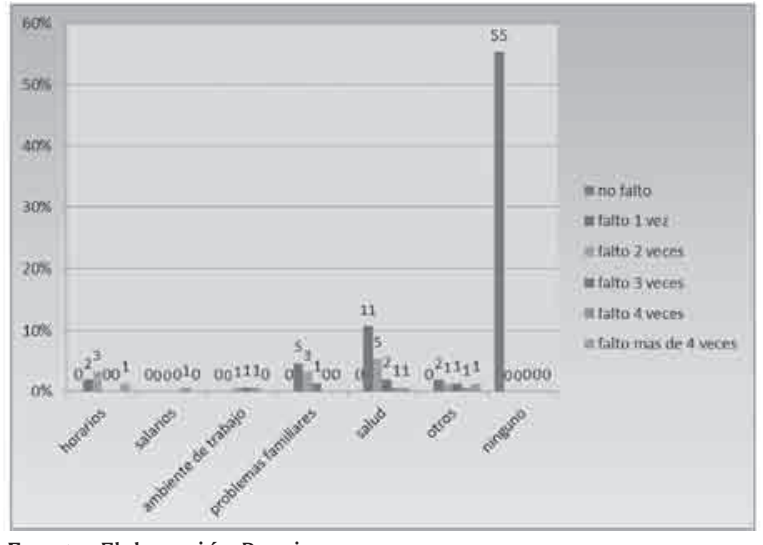

Fuente: Elaboración Propia

El 55\% de personas de un total de 150 encuestados que trabajan en el emporio comercial del Parque Industrial del distrito de Villa El Salvador no faltó en los últimos meses a su centro de trabajo. El $11 \%$ de personas de un total de 150 que laboran en el emporio del Parque Industrial faltó una vez por motivos de salud, el 5\% faltó una vez por problemas familiares; mientras aquellos que faltaron más de cuatro veces manifestaron diversos motivos: un $1 \%$ por horarios, $1 \%$ por salud y $1 \%$ por otros motivos como ocio y compromisos. En el caso del ausentismo sucede casi lo mismo que con la rotación, la mayoría de las personas teme perder su trabajo. En el mejor de los casos, sufrir algún tipo de descuento, por lo que hacen todo lo posible por no faltar.

Figura $\mathrm{N}^{\circ} 6$. Rotación versus edad de los trabajadores

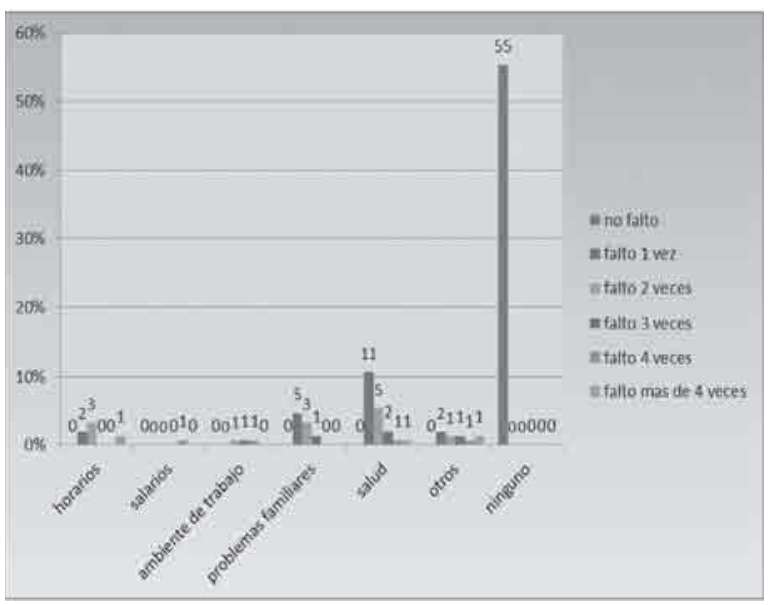

Fuente: Elaboración Propia 
Dentro de las personas que laboran en el emporio empresarial de Villa El Salvador que no cambiaron de trabajo en los últimos años, el 25\% tiene entre 18-27 años, el 16\% entre 27-35, el 8\% entre $35-44$, el $4 \%$ entre $44-53$ y el $3 \%$ tienen una edad mayor a 53 años.

De las personas que laboran en el emporio del Parque Industrial que cambiaron de trabajo por una vez en los últimos años, el 9\% tiene una edad entre $18-27$, el $9 \%$ entre $27-35$ y el $4 \%$ entre 35-44. De las personas que laboran en el emporio del Parque Industrial que cambiaron dos veces en los últimos años, el $8 \%$ tiene un rango de edad entre 18-27 años, el 6\% entre 27-35, el 1\% entre $35-44$ y un $1 \%$ entre 44 y 53 años. Mientras que las personas que trabajan en el Parque Industrial que cambiaron más de cuatro veces en los últimos años, tienen una proporción igual al $1 \%$ en los rangos de 18-17, 27-35, 35-44 y 44-53 años de edad. En el Gráfico $\mathrm{N}^{\circ} 5$ se observa que los índices de rotación disminuyen conforme la edad de las personas va en aumento, esto se debe a que la gran mayoría de las personas que trabaja en este emporio son personas relativamente jóvenes. Si bien es cierto, también existen personas mayores, éstas tienen una menor proporción. Por otro lado los trabajadores más jóvenes tienen mayores indicadores de rotación debido a que no poseen carga de familia, o no están muy comprometidos con su trabajo.

Figura $\mathrm{N}^{\circ} 7$. Ausentismo versus edad

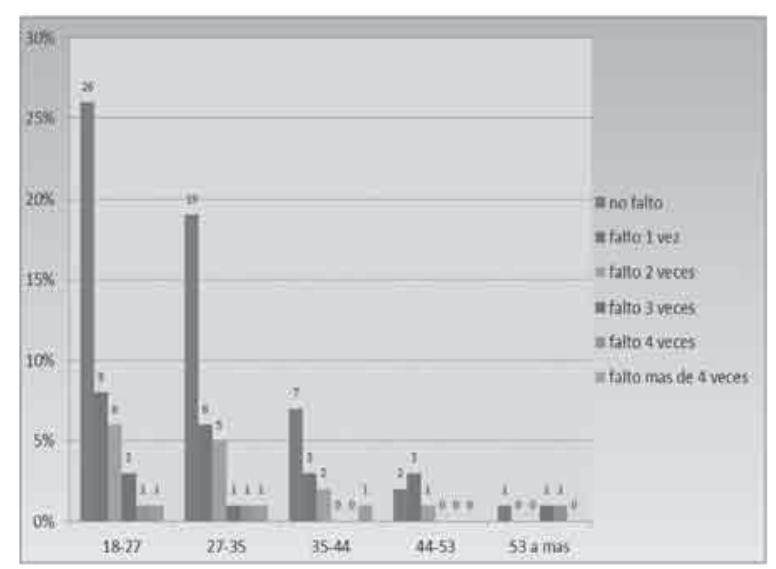

Fuente: Elaboración Propia

Dentro de las personas que laboran en el emporio comercial de Villa El Salvador, que no faltaron al trabajo en los últimos meses, el 26\% tiene entre 18-27 años, el 19\% entre $27-35$, el $7 \%$ entre $35-44$, el $2 \%$ entre $44-53$ y el $1 \%$ tienen una edad mayor a 53 años. De las personas que laboran en el emporio del Parque Industrial y que faltaron una vez en los últimos meses, el $8 \%$ tienen edades entre 18-27, el 6\% entre 27-35, el 7\% entre 35-44 y el 3\% entre 44-53 años. De las personas que laboran en el emporio del Parque Industrial que faltaron al trabajo dos veces en los últimos meses, el 6\% tienen un rango de edad entre 18-27 años, el $5 \%$ entre $27-35$, el $2 \%$ entre $35-44$ y un $1 \%$ entre 44 y 53 años. Mientras las personas que trabajan en el Parque Industrial que faltaron al trabajo más de cuatro veces en los últimos meses tienen una proporción igual al 1\% en los rangos de 18-17, 27-35 y 35-44 años de edad, respectivamente. En el caso del ausentismo sucede algo similar a la rotación: las personas con mayor rango de edad no tienen altos índices de ausentismo, debido a que los jóvenes no tienen mayores responsabilidades económicas, caso contrario sucede en las personas mayores, donde -casi en su totalidadtienen sobre sus hombros el sustento de la familia.

Figura $N^{\circ} 8$. Rotación versus sexo

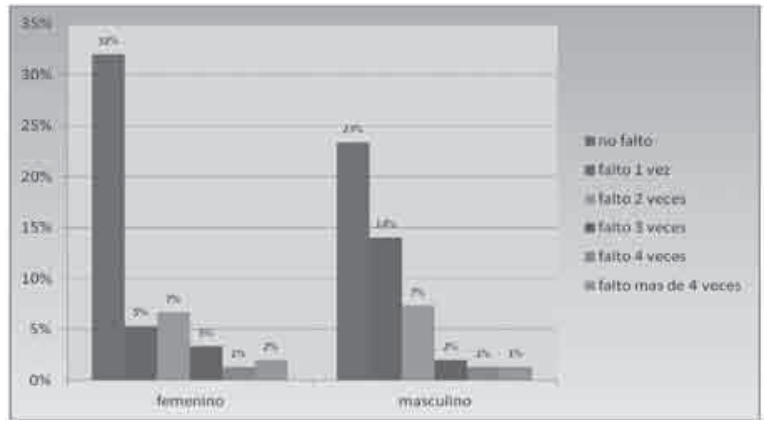

Fuente: Elaboración Propia

El 29\% de personas de un total de 150 que trabajan en el emporio comercial del Parque Industrial de Villa El Salvador no cambió de trabajo y son de sexo femenino, mientras que el $28 \%$ del total no cambió de trabajo y son de sexo masculino. Dentro de las personas que cambiaron de empleo por lo menos una vez y son de sexo femenino representa al $10 \%$ de un total de 150 personas que laboran en el Parque Industrial; el $8 \%$, dos veces; el $2 \%$ tres veces; el $1 \%$, cuatro veces y un $1 \%$ cambió más de cuatro veces.

Dentro de las personas que cambiaron de empleo por lo menos una vez, y que son de sexo masculino tenemos que el $12 \%$ de un total de 150 personas que laboran en el Parque Industrial, el $7 \%$ cambió dos veces; el $1 \%$, tres veces y un $1 \%$ cambió más de cuatro veces. La rotación laboral de mujeres y varones no tiene muchos puntos de diferencia, por lo que podemos deducir que ambos sexos presentan casi un mismo grado de estabilidad laboral. 
Figura $\mathbf{N}^{\circ} 9$. Ausentismo versus sexo

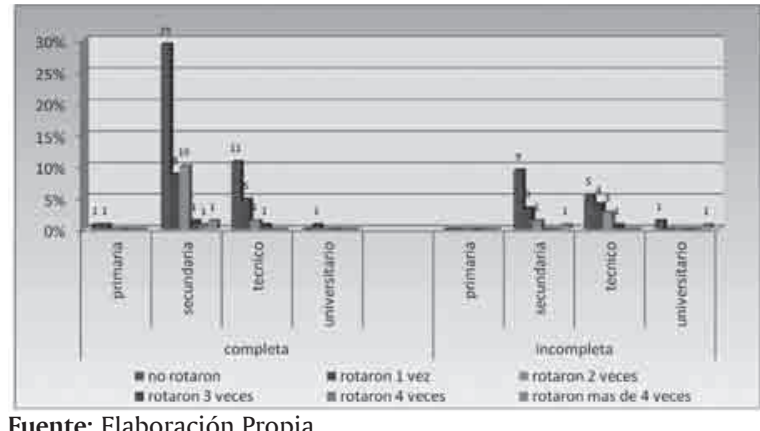

El 32\% de personas de un total de 150 que trabajan en el emporio empresarial del Parque Industrial de Villa El Salvador, no faltó al trabajo y son de sexo femenino, mientras que el $23 \%$ del total no faltó al trabajo y son de sexo masculino. Dentro de las personas que responden al sexo femenino y que faltaron al trabajo por lo menos una vez, son el $5 \%$ de un total de 150 personas; el $7 \%$, dos veces; el $3 \%$, tres veces; el $1 \%$, cuatro veces y un $2 \%$ faltó más de cuatro veces.

Dentro de las personas son de sexo masculino y que cambiaron de empleo por lo menos una vez corresponden al $14 \%$ de un total de 150 personas que laboran en el Parque Industrial; el 7\% cambió dos veces; el $2 \%$, tres veces; el $1 \%$, cuatro veces y un $1 \%$ faltó más de cuatro veces. La figura muestra que quienes más se ausentan del trabajo son las mujeres, de allí que podemos asumir que se debe a sus responsabilidades maternales y familiares.

Figura $\mathrm{N}^{\circ} 10$. Rotación versus grado de instrucción

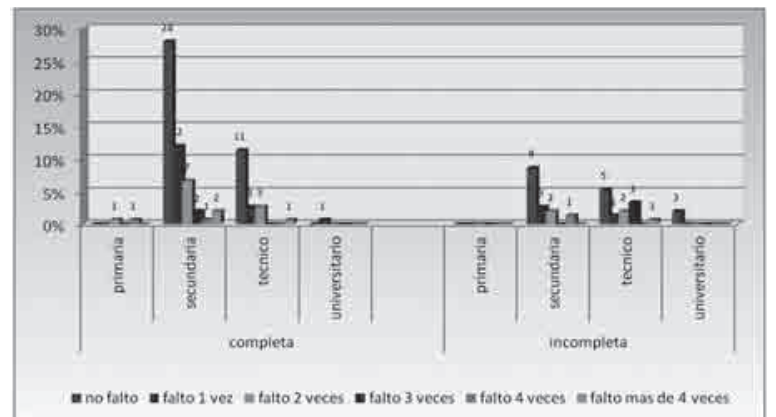

Fuente: Elaboración Propia

El 29\% de personas de un total de 150 que laboran en el emporio comercial del Parque Industrial del distrito de Villa El Salvador son los que estudiaron secundaria completa y no cambiaron de trabajo en los últimos años; mientras que un 9\% del total son los que estudiaron secundaria incompleta y tampoco cambiaron de trabajo. Dentro de los que estudiaron secundaria completa que cambiaron de trabajo en los últimos años tenemos el 9\% de personas de un total de 150 que trabajan en el emporio del Parque Industrial cambió de empleo una vez; el $10 \%$, dos veces; el $1 \%$, tres veces; el $1 \%$, cuatro veces y un $1 \%$ más de cuatro veces.

Dentro de los que terminaron sus estudios técnicos y cambiaron de trabajo en los últimos años tenemos el $5 \%$ de personas de un total de 150 que trabajan en el emporio del Parque Industrial cambió de empleo una vez; el 1\%, dos veces; y el $1 \%$, tres veces. Dentro de los que estudiaron secundaria incompleta y cambiaron de trabajo en los últimos años tenemos que el 3\% de personas de un total de 150 que trabajan en el emporio del Parque Industrial cambió de empleo una vez; el $1 \%$, dos veces; y un $1 \%$ más de cuatro veces.

Dentro de los que no terminaron sus estudios técnicos y cambiaron de trabajo en los últimos años tenemos que el $4 \%$ de personas de un total de 150 que trabajan en el emporio del Parque Industrial cambió de empleo una vez y el $1 \%$, dos veces. De allí vemos que los que menos rotan son los que han estudiado secundaria completa; el motivo puede ser que no tuvieron los recursos suficientes para continuar estudiando y valoran más un trabajo y buscan estabilidad.

Figura $N^{\circ} 11$. Ausentismo versus grado de instrucción

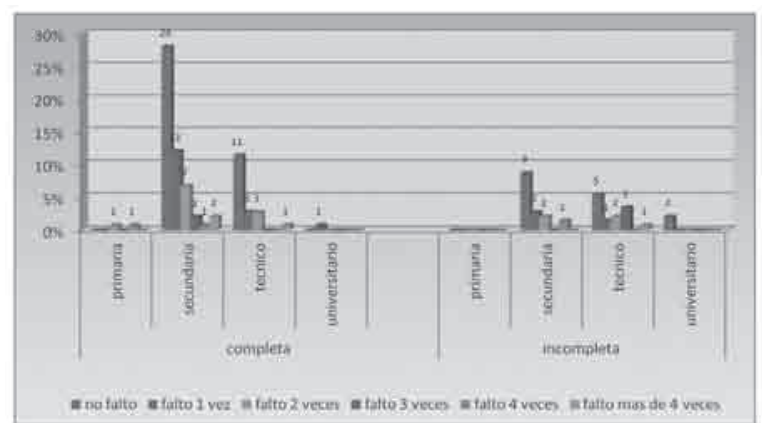

Fuente: Elaboración Propia

El 28\% de personas de un total de 150 que laboran en el emporio comercial del Parque Industrial del distrito de Villa El Salvador son los que estudiaron secundaria completa y no faltaron al trabajo en los últimos meses; mientras que un 9\% del total son los que estudiaron secundaria incompleta y tampoco faltaron al trabajo. De los que estudiaron secundaria completa y faltaron al trabajo en los últimos meses tenemos que el $12 \%$ de personas de un total de 150 que trabajan en el emporio del Parque Industrial faltó una vez; el 7\%, dos veces; el $2 \%$, tres veces; el $1 \%$, cuatro veces y un $2 \%$ más de cuatro veces.

Dentro de los que terminaron sus estudios técnicos y faltaron al trabajo en los últimos meses 
tenemos que el 3\% de personas de un total de 150 que trabajan en el emporio del Parque Industrial faltó una vez; el $3 \%$, dos veces y el $1 \%$ más de cuatro veces. Dentro de los que estudiaron secundaria incompleta y faltaron al trabajo en los últimos meses tenemos que el 3\% de personas de un total de 150 que trabajan en el emporio del Parque Industrial faltó una vez; el $2 \%$, dos veces; y un 1\%, cuatro veces. Dentro de los que no terminaron sus estudios técnicos y faltaron al trabajo en los últimos meses tenemos que el $4 \%$ de personas de un total de 150 que trabajan en el emporio del Parque Industrial faltó una vez; el $2 \%$, dos veces; el $3 \%$, tres veces; y el 1\%, más de cuatro veces. De manera general tenemos que los que se ausentan más son aquellos con estudios completos en los cuatro niveles. De tales resultados se deduce que siguen estudiando y por ello tienen más flexibilidad en horarios y permisos.

\section{Figura $\mathrm{N}^{\circ} 12$. Rotación versus satisfacción laboral}

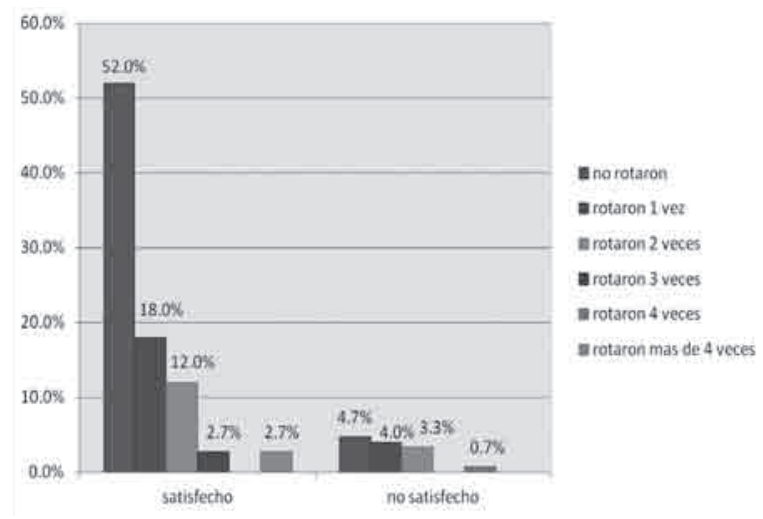

Fuente: Elaboración Propia

Las personas que laboran en el emporio comercial de Villa el Salvador y no cambiaron de trabajo en los últimos años por sentirse satisfechos en su centro laboral representan el $52 \%$ del total de trabajadores del dicho emporio empresarial. Mientras los que rotaron una vez a pesar de sentirse satisfechos, representan el $18 \%$ del total de trabajadores de dicho emporio empresarial. Por otra parte tenemos a los que no rotaron a pesar de sentirse insatisfechos en su centro laboral, que representan al 4,7\% del total de trabajadores de dicho emporio comercial. Como es lógico, los que se sienten satisfechos en su centro laboral no rotaron; en cambio, los que no se sienten satisfechos rotaron pero solo algunos. Esto se debe a que los trabajadores -aunque no se sientan satisfechossiguen en ese mismo trabajo por el factor salario y por el temor a no conseguir otro trabajo que sustente sus gastos.
Figura $\mathrm{N}^{\circ} 13$. Ausentismo versus satisfacción laboral



Fuente: Elaboración Propia

El 47,3\% de las personas de un total de 150 que trabajan y se sienten satisfechos en su centro laboral en el emporio comercial del Parque Industrial del distrito de Villa El Salvador manifestaron no haber faltado nunca dentro de estos dos meses a su centro de trabajo. Mientras que el $8 \%$ de las personas de un total de 150 que trabajan y no se sienten satisfechas en su centro laboral en el emporio comercial del Parque Industrial del distrito de Villa El Salvador, expresaron haber faltado al trabajo. La mayoría de las personas que no faltaron a su centro laboral son los que se sienten satisfechos o realizados en su centro laboral.

\section{COMPROBACIÓN DE HIPÓTESIS}

\section{Hipótesis A}

En esta hipótesis nos interesa saber si existe relación entre la rotación de los trabajadores de su centro laboral con su grado de instrucción. Para ello se propone:

Formulación de la hipótesis:

$H_{0}=$ La rotación de los trabajadores de su centro laboral es independiente del grado de instrucción.

$H_{1}=$ La rotación de los trabajadores de su centro laboral guarda relación con el grado de instrucción.

Nivel de significancia: Los datos de estas variables fueron clasificados en una tabla de contingencia para probar la hipótesis de independencia, además asumiremos un nivel de significación de $\alpha=5 \%$, con el siguiente grado de libertad:

$$
\begin{aligned}
& \text { g.l. }=(c-1)(r-1) \\
& \text { g.l. }=(2-1)(4-1) \\
& \text { g.l. }=3
\end{aligned}
$$


Estadística de prueba:

$X^{2}=\sum \frac{\left(f_{0}-f_{e}\right)}{f_{e}}$

Dónde:

$f_{0}=$ frecuencia de casilla (celda) observada.

$f_{\varepsilon}=$ frecuencia esperada o teórica.

La frecuencia observada se muestra en la siguiente tabla:

Tabla $\mathbf{N}^{\circ} 1$. Tabla de contingencia grado instrucción versus rotación

\begin{tabular}{|l|l|c|c|c|}
\hline & & \multicolumn{2}{|c|}{ rotación } & \multirow{2}{*}{ Total } \\
\hline \multirow{4}{*}{ Grado de instrucción } & & No rotaron & Si rotaron & \\
\cline { 2 - 5 } & Primaria & 6 & 12 & 18 \\
\cline { 2 - 5 } & Secundaria & 107 & 102 & 209 \\
\cline { 2 - 5 } & Técnico & 34 & 30 & 64 \\
\cline { 2 - 5 } & Universitario & 4 & 5 & 9 \\
\hline \multicolumn{2}{|l|}{ Total } & 151 & 149 & 300 \\
\hline
\end{tabular}

Fuente: Elaboración Propia

Valor crítico de la estadística de prueba: Primero determinamos el valor crítico de $X^{2}$ en la tabla de distribución de chi-cuadrado para la prueba de una sola cola con:

$$
\alpha=5 \% \text { y Grados de libertad }=(2-1)(4-1)=3
$$

Elvalor tabularde $X^{2}{ }_{\text {(critico })}=X^{2}{ }_{(0.05, a)}=7,815$

Figura $\mathrm{N}^{\circ} 14$. Valor crítico de la estadística de prueba - Hipótesis $\mathrm{A}$

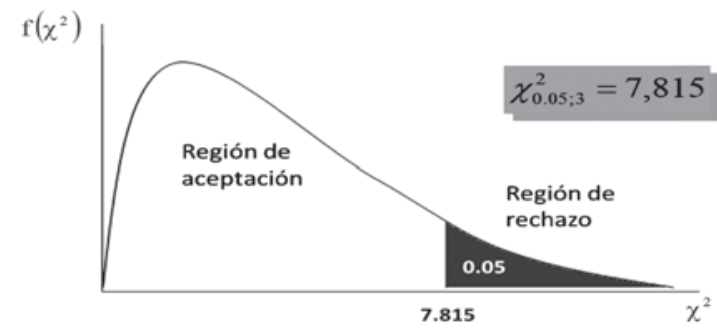

Fuente: Elaboración Propia

El valor crítico de la estadística de prueba es:

Tabla N². Pruebas de chi-cuadrado - Hipótesis A

\begin{tabular}{|l|c|c|c|}
\hline & Valor & gl & $\begin{array}{c}\text { Sig. asintótica } \\
\text { (bilateral) }\end{array}$ \\
\hline Chi-cuadrado de Pearson & $2,468^{\mathrm{a}}$ & 3 &, 481 \\
\hline Razón de verosimilitudes & 2,507 & 3 &, 474 \\
\hline Asociación lineal por lineal &, 548 & 1 &, 459 \\
\hline N de casos válidos & 300 & & \\
\hline
\end{tabular}

(a) Dos casillas $(25,0 \%)$ tienen una frecuencia esperada inferior a 5 .

La frecuencia mínima esperada es 4,47.

Fuente: Elaboración propia.

$$
X^{2}{ }_{(\text {calculado })}=2,468
$$

- Toma de decisión: Como el valor del estadístico de prueba (o chi-cuadrado experimental) es menor al valor tabular, esta se encuentra en la región de aceptación, se acepta $H_{0}$ y se rechaza $H_{1}$, por tanto la rotación de los trabajadores de su centro laboral no se ve influenciado por el grado de instrucción de estos.

\section{Hipótesis B}

En esta hipótesis nos interesa saber si existe relación entre la ausencia de los trabajadores en su centro laboral con el grado de instrucción de estos. Para ello se plantea lo siguiente:

- Formulación de la hipótesis:

$H_{0}=$ El ausentismo de los trabajadores en su centro laboral es independiente al grado de instrucción.

$H_{1}=$ El ausentismo de los trabajadores en su centro laboral guarda relación con el grado de instrucción.

- Nivel de significancia: Los datos de estas variables fueron clasificados en una tabla de contingencia para probar la hipótesis de independencia, además asumiremos un nivel de significación de $\alpha=5 \%$, con el siguiente grado de libertad:

$$
\begin{aligned}
& \text { g.l. }=(c-1)(r-1) \\
& \text { g.l. }=(2-1)(4-1) \\
& \text { g.l. }=3
\end{aligned}
$$

Estadística de prueba:

$$
X^{2}=\sum \frac{\left(f_{0}-f_{e}\right)}{f_{\varepsilon}}
$$

Dónde:

$f_{0}=$ frecuencia de casilla (celda) observada.

$f_{\varepsilon}=$ frecuencia esperada o teórica.

La frecuencia observada se muestra en la siguiente tabla:

Tabla $N^{\circ} 3$. Tabla de contingencia grado instrucción versus ausentismo

\begin{tabular}{|l|l|c|c|c|}
\hline & & \multicolumn{2}{|c|}{ ausentismo } & \multirow{2}{*}{ Total } \\
\hline \multirow{4}{*}{$\begin{array}{l}\text { Grado de } \\
\text { instrucción }\end{array}$} & Primaria & $\begin{array}{c}\text { No se ausen- } \\
\text { taron }\end{array}$ & $\begin{array}{c}\text { Se ausen- } \\
\text { taron }\end{array}$ & \\
\cline { 2 - 5 } & Secundaria & 96 & 16 & 18 \\
\cline { 2 - 5 } & Técnico & 37 & 113 & 209 \\
\cline { 2 - 5 } & Universitario & 6 & 27 & 64 \\
\hline Total & 141 & 3 & 9 \\
\hline \multirow{2}{*}{ Fuente: Elaboración Propia } & \multicolumn{4}{|l}{} \\
\hline
\end{tabular}


Valor crítico de la estadística de prueba: Primero determinamos el valor crítico de $X^{2}$ en la tabla de distribución de chi-cuadrada para la prueba de una sola cola con:

$\alpha=5 \%$ y Grados de libertad $=(2-1)(4-1)=3$

Elvalor tabular de $X_{(\text {critico })}=X_{(0,05,3)}^{2}=7,815$

Figura $\mathrm{N}^{\circ} 15$. Valor crítico de la estadística de prueba - Hipótesis B

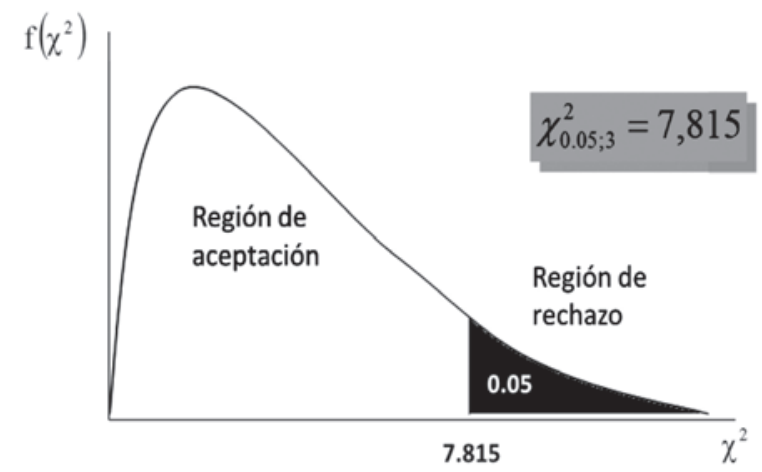

Fuente: Elaboración propia.

El valor crítico de la estadística de prueba es:

Tabla Nº . Pruebas de chi-cuadrado - Hipótesis B

\begin{tabular}{|l|c|c|c|}
\hline & Valor & gl & $\begin{array}{c}\text { Sig. asintótica } \\
\text { (bilateral) }\end{array}$ \\
\hline Chi-cuadrado de Pearson & $13,804^{\mathrm{a}}$ & 3 &, 003 \\
\hline Razón de verosimilitudes & 15,287 & 3 &, 002 \\
\hline Asociación lineal por lineal & 10,977 & 1 &, 001 \\
\hline N de casos válidos & 300 & & \\
\hline
\end{tabular}

(a) Dos casillas $(25,0 \%)$ tienen una frecuencia esperada inferior a 5 .

La frecuencia mínima esperada es 4,23.

Fuente: Elaboración propia.

$X_{\text {(calculado })}^{2}=13,804$

- Toma de decisión: Como el valor del estadístico de prueba (o chi-cuadrado experimental) es mayor al valor tabular, esta se ubica en la región de rechazo, se rechaza $H_{0}$ y se acepta $H_{1}$, por lo tanto el ausentismo de los trabajadores en su centro laboral se ve influenciado por el grado de instrucción de estos.

\section{Hipótesis C}

En esta hipótesis nos interesa saber si existe relación entre la rotación de los trabajadores de su centro laboral con el grado de satisfacción. Para ello se plantea lo siguiente:

- Formulación de la hipótesis:

$H_{0}=$ La rotación de los trabajadores de su centro laboral guarda relación con el grado de satisfacción.

$H_{1}=$ La rotación de los trabajadores de su centro laboral es independiente al grado de satisfacción.

- Nivel de significancia: Los datos de estas variables fueron clasificados en una tabla de contingencia para probar la hipótesis de independencia, además asumiremos un nivel de significación de $\alpha=5 \%$, con el siguiente grado de libertad:

$$
\begin{aligned}
& \text { g.l. }=(c-1)(r-1) \\
& \text { g.l. }=(2-1)(2-1) \\
& \text { g.l. }=1
\end{aligned}
$$

- Estadística de prueba:

$$
X^{2}=\sum \frac{\left(f_{o}-f_{e}\right)}{f_{e}}
$$

Dónde:

$f_{o}=$ frecuencia de casilla (celda) observada

$f_{\varepsilon}=$ frecuencia esperada o teórica

La frecuencia observada se muestra en la siguiente tabla:

Tabla $N^{\circ} 5$. Tabla de contingencia satisfecho versus rotación

\begin{tabular}{|l|l|l|l|l|}
\hline & & rotación & Total & \\
\hline & & No rotaron & Si rotaron & \\
\hline satisfecho & $\mathrm{Si}$ & 127 & 117 & 244 \\
\hline & $\mathrm{No}$ & 24 & 32 & 56 \\
\hline Total & 151 & 149 & 300 & \\
\hline
\end{tabular}

Fuente: Elaboración propia.

Valor crítico de la estadística de prueba: Primero determinamos el valor crítico de $X^{2}$ en la tabla de distribución de chi-cuadrado para la prueba de una sola cola con:

$$
\begin{aligned}
& \alpha=5 \% \text { y Grados de libertad }=(2-1)(2-1)=1 \\
& \text { Elvalor tabularde } X_{(\text {critico) }}=X_{(0,05,1)}^{2}=3,841
\end{aligned}
$$

Figura $\mathbf{N}^{\circ} \mathbf{1 6}$. Valor crítico de la estadística de prueba - Hipótesis C

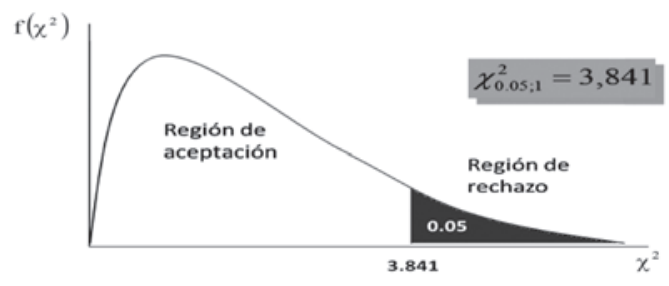

Fuente: Elaboración propia. 
El valor crítico de la estadística de prueba es:

Tabla Nº6. Pruebas de chi-cuadrado - Hipótesis C

\begin{tabular}{|l|c|c|c|}
\hline & Valor & gl & $\begin{array}{c}\text { Sig. asintótica } \\
\text { (bilateral) }\end{array}$ \\
\hline Chi-cuadrado de Pearson & $1,539^{\mathrm{a}}$ & 1 &, 215 \\
\hline Corrección por continuidad & 1,194 & 1 &, 275 \\
\hline Razón de verosimilitudes & 1,543 & 1 &, 214 \\
\hline Estadístico exacto de Fisher & & & \\
\hline Asociación lineal por lineal & 1,534 & 1 &, 215 \\
\hline N de casos válidos & 300 & & \\
\hline
\end{tabular}

(a) 0 casillas $(0,0 \%)$ tienen una frecuencia esperada inferior a 5 .

La frecuencia mínima esperada es 27,81 .

(b) Calculado sólo para una tabla de $2 \times 2$.

Fuente: Elaboración propia.

$X^{2}{ }_{\text {(calculado) }}=1,539$

- Toma de decisión: Como el valor del estadístico de prueba (o chi-cuadrado experimental) es menor al valor tabular, esta se ubica en la región de aceptación, se acepta $H_{0}$ y se rechaza $H_{1}$, por lo tanto la rotación de los trabajadores de su centro laboral se ve influenciado por el grado de satisfacción.

\section{Hipótesis D}

En esta hipótesis nos interesa saber si existe relación entre la ausencia de los trabajadores en su centro laboral con el grado de satisfacción. Para ello se plantea lo siguiente:

Formulación de la hipótesis:

$H_{0}=$ El ausentismo de los trabajadores en su centro laboral es independiente al grado de satisfacción.

$H_{1}=$ El ausentismo de los trabajadores en su centro laboral guarda relación con el grado de satisfacción.

Nivel de significancia: Los datos de estas variables fueron clasificados en una tabla de contingencia para probar la hipótesis de independencia, además asumiremos un nivel de significación de $\alpha=5 \%$, con el siguiente grado de libertad:

$$
\begin{aligned}
& \text { g.l. }=(c-1)(r-1) \\
& \text { g.l. }=(2-1)(4-1), \text { g.l. }=3
\end{aligned}
$$

Estadística de prueba:

$$
X^{2}=\sum \frac{\left(f_{o}-f_{e}\right)}{f_{e}}
$$

Dónde:

$f_{o}=$ frecuencia de casilla (celda) observada

$f_{\varepsilon}=$ frecuencia esperada o teórica

La frecuencia observada se muestra en la siguiente tabla:

Tabla $\mathrm{N}^{\circ} 7$. Tabla de contingencia satisfecho versus ausentismo

\begin{tabular}{|l|c|c|c|c|}
\hline & & \multicolumn{2}{|c|}{ Ausentismo } & \multirow{2}{*}{ Total } \\
\hline & & No se ausentaron & Se ausentaron & \\
\hline \multirow{2}{*}{ Satisfecho } & $\mathrm{Si}$ & 107 & 137 & 244 \\
\cline { 2 - 5 } & No & 34 & 22 & 56 \\
\hline Total & & 141 & 159 & 300 \\
\hline
\end{tabular}

Fuente: Elaboración propia.

- Valor crítico de la estadística de prueba: Primero determinamos el valor crítico de $X^{2}$ en la tabla de distribución de chi-cuadrado para la prueba de una sola cola con:

$\alpha=5 \%$ y Grados de libertad $=(2-1)(2-1)=1$

Elvalor tabularde $X^{2}{ }_{(\text {critico })}=X_{(0.05,1)}^{2}=3,841$

Figura $\mathrm{N}^{\circ} 17$. Valor crítico de la estadística de prueba - Hipótesis D

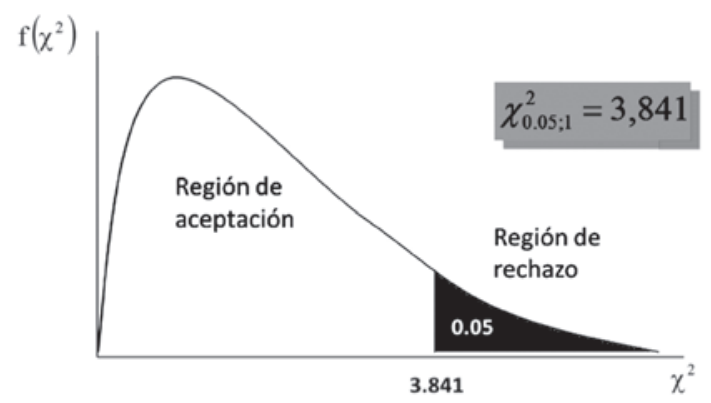

Fuente: Elaboración propia.

El valor crítico de la estadística de prueba es:

\begin{tabular}{|c|c|c|c|c|c|}
\hline & Valor & $\mathrm{gl}$ & $\begin{array}{l}\text { Sig. asintóti- } \\
\text { ca (bilateral) }\end{array}$ & $\begin{array}{c}\text { Sig. exacta } \\
\text { (bilateral) }\end{array}$ & $\begin{array}{l}\text { Sig. exacta } \\
\text { (unilateral) }\end{array}$ \\
\hline Chi-cuadrado de Pearson & $5,199^{a}$ & 1 & 023 & & \\
\hline Corrección por continuidad ${ }^{b}$ & 4,544 & 1 & 033 & & \\
\hline Razón de verosimilitudes & 5,209 & 1 &, 022 & & \\
\hline Estadístico exacto de Fisher & & & & ,026 & ,016 \\
\hline Asociación lineal por lineal & 5,181 & 1 & 023 & & \\
\hline N de casos válidos & 300 & & & & \\
\hline
\end{tabular}

Tabla N ${ }^{\circ}$. Pruebas de chi-cuadrado - Hipótesis D

(a) 0 casillas $(0,0 \%)$ tienen una frecuencia esperada inferior a 5 . La frecuencia mínima esperada es 26,32.

(b) Calculado sólo para una tabla de $2 \times 2$.

Fuente: Elaboración propia. 


$$
X_{(\text {calculado) }}^{2}=5,199
$$

Toma de decisión: Como el valor del estadístico de prueba (o chi-cuadrado experimental) es mayor al valor tabular, esta está en la región de rechazo, se rechaza $H_{0}$ y se acepta ${ }_{1}$, por lo tanto el ausentismo de los trabajadores en su centro laboral se ve influenciado por el grado de satisfacción.

\section{CONCLUSIONES}

Después de analizar los resultados del trabajo de campo en concordancia con los objetivos planteados las siguientes son las conclusiones de la presente investigación:

- La importancia de la investigación radica en su nivel de aplicabilidad para mejorar la productividad de los colaboradores. En las empresas que conforman el PIVES, sí es posible reducir las tasas de rotación y ausentismo si se aplican las recomendaciones que forman parte de la presente investigación.

- Los resultados nos indican claramente que existe un alto grado de ausentismo que se acerca al $30 \%$ del total de la muestra, manifestando que esto se debe principalmente a problemas familiares y a temas de salud representados por el $29,41 \%$ y $28,48 \%$ respectivamente. El salario y clima laboral son determinantes para que los colaboradores falten a su centro laboral, así como las causas exógenas.

- Los resultados también revelan las personas que se ubican en el rango de 18 y 27 años son las que rotan con mayor frecuencia, expresado con el 58,5\%. De la misma forma, los trabajadores jóvenes son las que más se ausentan de sus centros laborales con un 49,2\%. En contraste, los trabajadores mayores de 53 años muestran total fidelidad a sus empresas, por cuanto su rotación solo llega al $0,8 \%$.

- Queda claro que la rotación y el ausentismo son dos indicadores que miden el impacto de la gestión humana. Estos fenómenos se presentan en cualquier empresa. El reto para los directivos y/o ejecutivos es cómo gestionar para convertir aquello que puede presentarse como una debilidad en una fortaleza, que permita fortalecer y energizar sus áreas de trabajo.

\section{RECOMENDACIONES}

- Como se mencionó anteriormente la rotación laboral o el dinamismo demasiado rápido en el mercado laboral significa altos costos para las empresas. Un colaborador que renuncie significa una pérdida en el know how ${ }^{5}$ de la organización, costos de entrenamiento o capacitación y los costos que implica encontrar otro trabajador que desempeñe similares funciones, con el riesgo de que no sea el más idóneo. De allí que es indispensable que los empresarios tomen nota de los hallazgos de la presente investigación para disminuir la rotación.

- En relación al ausentismo laboral, se recomienda desarrollar estrategias y políticas que nos permitan disminuir los niveles de ausentismo provenientes de la insatisfacción por salario y ambiente laboral.

- Creemos que tanto la rotación como el ausentismo se pueden reducir a través de cinco pilares que se presentan como políticas empresariales, y estos son:

- Salario. Incrementar los ingresos salariales de los trabajadores hará que se sientan satisfechos en su centro laboral, aunque esta lógica es un poco subjetiva porque el salario dependerá de las expectativas de los trabajadores en relación a la función que desempeñan. Una vez que estos se sientan satisfechos, su propensión marginal a rotar de una empresa a otra disminuirá.

- Clima organizacional. Generar un ambiente laboral llevadero y placentero donde los trabajadores se sientan a gusto trabajando (Baguer, 2009, p. 148). Un buen clima laboral es aquel donde las personas trabajan en entornos armoniosos, donde los colaboradores desarrollan sus habilidades y competencias. La organización cuyo clima organizacional se encuentre en armonía tendrá mayores oportunidades de retener a sus trabajadores y así aminorar sus costos por rotación y ausentismo laboral.

- Beneficios sociales. Otra forma de reducir la rotación y ausentismo de los trabajadores es implementar una política concesionaria en la empresa en beneficio de sus

5 Término utilizado por la teoría administrativa o de gestión para referirse a los conocimientos preexistentes en la organización, conocimientos académicos, técnicos, experiencias y otros. 
trabajadores, en este caso, brindándoles beneficios sociales tales como vacaciones y descansos, gratificaciones, participación en los resultados, seguro de vida, entre otros; así los trabajadores se sentirán más seguros y permanecerán estables en su puesto de trabajo.

- Oportunidades de desarrollo profesional y aprendizaje. Todos los factores de retención de los trabajadores deben ir acompañado de las oportunidades de desarrollo profesional. La empresa debe proporcionar recursos y apoyo a las iniciativas para que cada empleado alcance el éxito en su trabajo, además de establecer canales de información que permitan conocer en nuestros colaboradores sus expectativas en el desempeño y rendimiento en la organización. En ese orden de ideas, la empresa debe invertir en el desarrollo de cada trabajador mediante cursos, seminarios, talleres que se impartan en todos los niveles de la organización en colaboración con otras entidades externas especializadas en los temas. En esto las universidades, institutos tecnológicos o consultoras, pueden ser alternativas viables.

- Motivación. La motivación resulta una variable importante para el desempeño de la organización. En el caso del análisis del ausentismo, esta contribuirá a disminuir sus índices. La motivación se desenvolverá como una estrategia organizacional tratando de ofrecer incentivos, premios a los trabajadores por su buen desempeño, entre otras, además de tratar de maximizar la satisfacción de las necesidades de los trabajadores $^{6}$ para fomentar que los trabajadores no falten. Se sugiere combinar motivaciones que satisfagan necesidades intrínsecas con las extrínsecas.

- Hay otras opciones para aminorar la pérdida del know how en la empresa como producto de la rotación laboral, como implementar un sistema que permita gestionar el conocimiento de la empresa, modelo que ha cobrado mucho énfasis en estos últimos años y que resulta de relevancia para el desarrollo organizacional. La gestión del conocimiento, es un nuevo paradigma dentro de la teoría administrativa que se configura como un sistema para administrar la recopilación, organización, refinamiento, análisis y diseminación o difusión del conocimiento de cualquier tipo dentro de una organización. La eficiente gestión del conocimiento donde el principal recurso es el capital intelectual de la empresa, permitirá acumular conocimientos a pesar de la fuga de talentos, evitando que se incurran en pérdidas importantes para la competitividad de la organización.

\section{LITERATURA CITADA}

Aamodt, Michael. (2010). Psicología industrial/organizacional. Sexta edición. Editorial Cengage Learning, México DF.

Baguer Alcalá, Ángel. (2009). Dirección de personas. Editorial Mc Graw Hill, España.

Bohlander, George. (2001). Administración de recursos humanos. Décima segunda edición. Editorial Thomson, México DF.

Chiavenato, Idalberto. (2007). Administración de recursos humanos. Octava edición. Editorial Mc Graw Hill, México DF.

Diario El Comercio. (2011). "El Perú tiene el más alto índice de rotación laboral en Latinoamérica”. [En línea]. 02 de septiembre del 2011. Fecha de consulta: 02/09/2011. Disponible en: <http://elcomercio.pe/impresa/notas/ peru-tiene-mas-alto-indice-rotacion-laboral-latinoamerica/20110324/732011>.

Diccionario de la Real Academia Española. (2011). "Ausentismo". Fecha de consulta: 22/11/2012. Disponible en: <http:// buscon.rae.es/drael/SrvltConsulta?TIPO_ $\mathrm{BUS}=3 \& \mathrm{LEMA}=$ ausentismo $>$.

Morán, Consuelo. (2005). Psicología del trabajo. Ediciones Aljibe, Lima.

MTPE - Programa de Estadísticas y Estudios Laborales (2010). Informe Laboral. Ministerio de Trabajo y Promoción del Empleo, Lima.

Muchinsky, Paul. (2007). Psicología aplicada al trabajo. Octava edición. Editorial Cengage Learning, México DF.

6 La autorrealización es la última etapa (pico) de la Pirámide de Maslow: jerarquía de necesidades 
OIT y Universidad Nacional Autónoma de México. (2008). Absentismo laboral: el alto costo de un mundo enfermo. Editorial Mc Graw Hill, Mexico DF.

Ramírez de la Roche, Omar. (2007). "Ausentismo laboral: el alto costo de un mundo enfermo". En: Atención familiar. Vol. 14(6). Noviembre-diciembre del 2007, pp. 139 -140. Departamento de Medicina Familiar, Facultad de Medicina, Universidad Nacional Autónoma de México, México DF.

Reyes, Agustín. (2000). Administración de personal. Trigésima edición. Editorial Limusa, México DF.

Rincón Zaragoza, Pablo. (2008). La motivación laboral como herramienta clave para evitar la rotación de personal en las empresas de Servicios de la Ciudad de Morelia. [PDF]. Tesis para obtener el título de .... Facultad de Administración, Universidad de Morelia, México DF.

Robbins, Stephen. (2009). Comportamiento organizacional. Décimo tercera edición. Editorial Pearson Prentice Hall, México DF.

Rojas, Karen. (s.f.). “Rotación Laboral”. En: Conocimientosweb.net. Fecha de consulta: 21/10/2012. Disponible en: <http:/www. conocimientosweb.net/zip/article 1938. html $>$.

Romo, Marta y Rodríguez, Nekane. (2010). Traza tu rumbo. Primera edición. Editorial Lid Empresarial, Madrid. 